\title{
8-Iso-Prostaglandin F2 Alpha Measurement
}

National Cancer Institute

\section{Source}

National Cancer Institute. 8-Iso-Prostaglandin F2 Alpha Measurement. NCI Thesaurus.

Code C119292.

The determination of the amount of 8-iso-prostaglandin F2 alpha in a biological specimen. 